\title{
ASSESSMENT OF STAGE APPROPRIATE MEDICAL CARE GIVEN TO COPD PATIENTS IN PERIPHERAL HEALTH CARE SYSTEMS
}

\author{
Ronald Win B1, Minu Krishnan ${ }^{2}$ \\ ${ }^{1}$ Additional Professor, Department of Pulmonary Medicine, Government Medical College, Trivandrum, Kerala. \\ ${ }^{2}$ Assistant Surgeon, Kerala Government Health Service.
}

\section{ABSTRACT}

\section{BACKGROUND}

Among all major chronic diseases, COPD is the only disease that shows a rising mortality. Estimates show that COPD will become the third leading cause of death worldwide by 2030. While analysing the history and records of patients, it is evident that majority of COPD patients were getting treatment, which were different from the currently accepted guidelines.

Aim of the Study- To determine the proportion of COPD patients getting treatment as per currently accepted guidelines from peripheral health care systems.

\section{MATERIALS AND METHODS}

Institution based cross-sectional study conducted in the Department of Pulmonary Medicine, Medical College, Trivandrum from March 2012 to November 2013. Study population constitutes patients who were referred from peripheral health centres with the diagnosis of COPD and confirmed as COPD in the study. They were evaluated with a structured questionnaire after taking consent. Patients with no medical records were excluded.

\section{RESULTS}

We assessed the stage appropriate management of COPD from peripheral health care systems under five categories, i.e. smoking cessation, pharmacotherapy, vaccination, pulmonary rehabilitation and home oxygen therapy. Out of the 144 subjects, stage appropriate pharmacotherapy is seen in $19.7 \%$ and $81.6 \%$ had received at least one of the non-recommended medications. And none of the patients had a Pulmonary function testing done. None of the medical officers working in the peripheral health care centres had followed the " 5 As" of smoking cessation programme. Pulmonary rehabilitation was not prescribed to any of the COPD patients. Vaccination with Pneumococcal and Influenza vaccine was not given to any COPD patients. And finally none of the COPD is receiving home oxygen from peripheral health care centres. Also, we tried to assess the awareness about COPD among the patients and results are quite disappointing.

\section{CONCLUSION}

Even though GOLD guidelines of COPD have been accepted worldwide, the dissemination and application of these guidelines at peripheral level in India is not happening.

\section{KEYWORDS}

Stage Appropriate Medical Care, COPD Patients, Peripheral Health Systems.

HOW TO CITE THIS ARTICLE: Win RB, Krishnan M. Assessment of stage appropriate medical care given to COPD patients in peripheral health care systems. J. Evolution Med. Dent. Sci. 2017;6(30):2466-2470, DOI: 10.14260/Jemds/2017/532

\begin{abstract}
BACKGROUND
Chronic Obstructive Pulmonary Disease (COPD) is a common preventable and treatable disease characterised by persistent airflow limitation that is usually progressive and associated with an enhanced chronic inflammatory response in the airways and the lung to noxious particles or gases. Exacerbations and comorbidities contribute to the overall severity in individual patients. COPD is a major cause of morbidity and mortality worldwide and is one among the top ten contributors to the global burden of disease. Many people suffer from this disease for years and die prematurely from it or its complications. ${ }^{1}$
\end{abstract}

Financial or Other, Competing Interest: None.

Submission 08-03-2017, Peer Review 02-04-2017,

Acceptance 07-04-2017, Published 13-04-2017.

Corresponding Author:

Dr. Ronald Win B,

Additional Professor,

Department of Pulmonary Medicine,

Government Medical College, Trivandrum.

E-mail: ronaldwin_b@yahoo.co.in

DOI: $10.14260 /$ jemds $/ 2017 / 532$

\section{(c) $(i) \$$}

Among all major chronic diseases, COPD is the only disease that shows a rising mortality. Globally, the COPD burden is projected to increase in coming decades because of continued exposure to COPD risk factors and aging of the population. ${ }^{2}$ Because of its chronic and progressive nature, COPD represents a massive and growing burden in direct and indirect costs. In developing countries where smoking continues to be extremely prevalent, the health and economic burdens are higher than in developed nations. The disability caused by COPD in such countries further magnifies the problem. In 2002, COPD was the fifth leading cause of death. At present COPD is the fourth leading cause of death worldwide. Total deaths from COPD are projected to increase by more than $30 \%$ in the next 10 years unless urgent action is taken to reduce the underlying risk factors, especially tobacco use. Estimates show that COPD becomes in 2030 the third leading cause of death worldwide. ${ }^{3}$

Diagnosis of COPD should be considered in any patient who has symptoms of a chronic cough, sputum production, dyspnoea and a history of exposure to risk factors for the disease. 
There are over 40 different guidelines from different countries on diagnosis and management of Chronic Obstructive Pulmonary Disease. The guidelines formulated by the Global Initiative for Chronic Obstructive Lung Disease are perhaps the most popular and global in nature. GOLD guidelines have proposed four main components of COPD management: (i) Assessing and monitoring disease, (ii) Reducing the risk factors, (iii) Managing stable COPD, and (iv) Managing exacerbations. Comprehensive management for COPD includes advice and support for smoking cessation, early diagnosis, education and self-management, timely implementation of effective management strategies and multidisciplinary pulmonary rehabilitation programmes. ${ }^{4}$

The earliest study to determine the prevalence of COPD in India was carried out by Wig et al in 1964 in rural Delhi. 5 The prevalence in his study was 3.36 percent in males and 2.54 percent in females. Viswanathan in 1966 reported 2.12 percent prevalence in males and 1.33 percent in females in Patna. ${ }^{6}$ Later Radha and Colleagues noticed that the prevalence in New Delhi in 1977 was 8.1 percent in men and 4.6 percent in women. ${ }^{7}$ Jindal in 1993 reported that the prevalence was 6.2 percent in men and 3.9 percent in women in rural area, and 4.2 and 1.6 percent respectively in urban area. ${ }^{8}$ One of the study from South India (Madras) by Thiruvengadam et al in 1977 reported the prevalence of COPD of 1.9 percent in males and 1.2 percent in females 9 . And then Ray et al in 1995 found that the prevalence was 4.08 percent in males and 2.55 percent in females from south India. ${ }^{10}$ Recently, the Indian Study on Epidemiology of Asthma, Respiratory Systems and Chronic Bronchitis in Adults (INSEARECH) involving a total of 85105 men, 84470 women from 12 urban and 11 rural sites was published. ${ }^{11}$ According to this study, the overall prevalence of chronic bronchitis in adults $>35$ yrs. was 3.49 percent. There are wide variations in the prevalence of COPD within Indian subcontinent. The National burden of chronic bronchitis in this study was estimated as 14.84 million.

While analysing the history and records of patients, it is evident that majority of COPD patients were getting treatment, which were different from the currently accepted guidelines. Even though smoking cessation is the most cost effective intervention in the management of COPD, it seems that this is not effectively implemented at all levels of health care system.

In this study, we are trying to determine the proportion of COPD patients getting treatment as per currently accepted guidelines from peripheral health care systems.

\section{Aim of Study}

To determine the proportion of COPD patients getting treatment as per currently accepted guidelines from peripheral health care systems.

\section{MATERIALS AND METHODS}

Institution based cross-sectional study conducted in the Department of Pulmonary Medicine, Government Medical College, Trivandrum from March 2012 to November 2013. Study population constitutes patients who were referred from peripheral health centres with the diagnosis of COPD and confirmed as COPD in this study. A clinical diagnosis of COPD was established based on GOLD Guidelines and should be considered in any patient who has dyspnoea, chronic cough or sputum production and/or a history of exposure to risk factors for the disease. The diagnosis was confirmed by spirometry. The presence of post bronchodilator FEVI/FVC < 0.70 confirms the presence of airflow limitation that is not fully reversible. Further classification as stage 1 mild, stage 2 moderate, stage 3 severe and stage 4 very severe was done based on both criteria.

Patients who were not willing to take part in the study and without medical records were excluded. Sample size was calculated based on the proportion of patients with prevalence (proportion) of stage appropriate medications and management strategies- $40 \%$ (Based on the study published in the Journal- Today's Hospitalist, September 2006 by Deborah Gesensway, USA). With $95 \%$ confidence and $2 \%$ relative precision, sample size was calculated as 144 . All COPD patients fulfilling the inclusion criteria are recruited after taking consent, detailed history and clinical examination for every patient to arrive at a diagnosis. All previous medical records were collected and subjected the patient for spirometry to confirm the diagnosis. These patients were evaluated with a structured questionnaire.

The information collected include patient's awareness regarding COPD, medical care received from peripheral health care centre and details of smoking cessation efforts of treating physician. The tools used to study includes designed questionnaire and GOLD guidelines. In the method of analysis, quantitative variables will be represented as Arithmetic mean and standard deviation. Categorical variables will be represented as number of patients in each category. Percentage calculated from the formula $\%=$ No. of quality prescriptions/Total No. of subjects recruited x 100 . Results obtained are categorised under five headings Smoking cessation, Pharmacotherapy, Vaccination, Pulmonary rehabilitation and Home oxygen therapy.

\section{RESULTS}

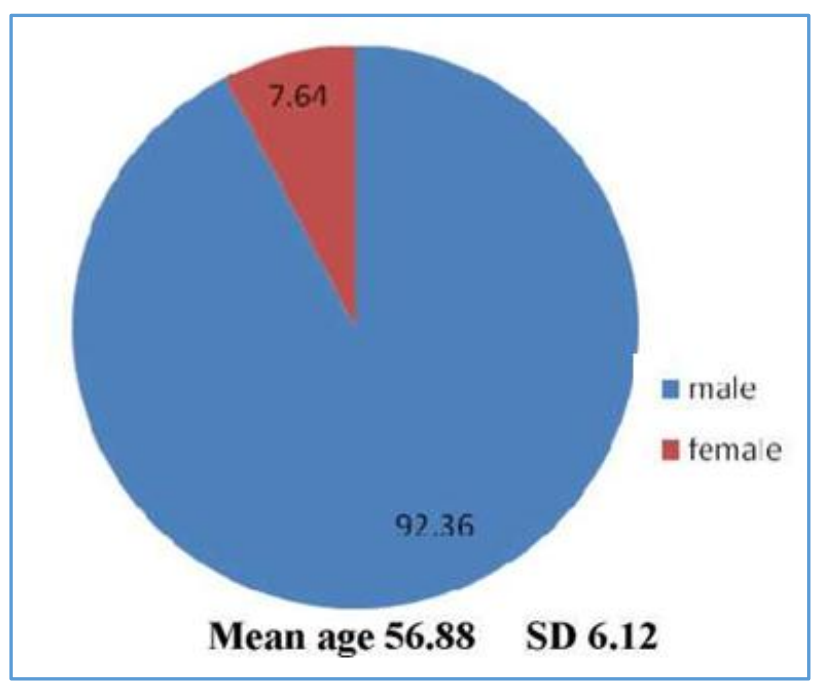

Table 1. Sex Distribution

\begin{tabular}{|c|c|c|}
\hline & Frequency & Percentage \\
\hline RURAL & 138 & 95.83 \\
\hline URBAN & 6 & 4.17 \\
\hline TOTAL & $\mathbf{1 4 4}$ & $\mathbf{1 0 0}$ \\
\hline \multicolumn{3}{|c|}{ Table 2. Residence } \\
\hline
\end{tabular}




\begin{tabular}{|c|c|c|}
\hline & Frequency & Percentage \\
\hline Manual Labour & 139 & 96.53 \\
\hline Skilled Work & 0 & 0 \\
\hline Office Job & 0 & 0 \\
\hline House Wife & 5 & 3.47 \\
\hline Total & $\mathbf{1 4 4}$ & $\mathbf{1 0 0}$ \\
\hline \multicolumn{3}{|c|}{ Table 3. Occupation } \\
\hline
\end{tabular}

\begin{tabular}{|c|c|c|}
\hline & Frequency & Percentage \\
\hline Current Smoker & 79 & 54.86 \\
\hline Ex-Smoker & 60 & 41.67 \\
\hline Never Smoker & 5 & 3.47 \\
\hline Total & $\mathbf{1 4 4}$ & $\mathbf{1 0 0}$ \\
\hline \multicolumn{2}{|c|}{ Table 4. Smoking Status } \\
\hline
\end{tabular}

\begin{tabular}{|c|c|c|}
\hline & Frequency & Percentage \\
\hline Yes & 144 & 100 \\
\hline No & 0 & 0 \\
\hline Total & $\mathbf{1 4 4}$ & $\mathbf{1 0 0}$ \\
\hline \multicolumn{3}{|c|}{ Table 5. History of Passive Smoking } \\
\hline
\end{tabular}

\begin{tabular}{|c|c|c|}
\hline & Frequency & Percentage \\
\hline Yes & 42 & 29.17 \\
\hline No & 102 & 70.83 \\
\hline Total & $\mathbf{1 4 4}$ & $\mathbf{1 0 0}$ \\
\hline \multicolumn{3}{|c|}{ Table 6. Inhaler Initiated? } \\
\hline
\end{tabular}

\begin{tabular}{|c|c|c|}
\hline & Frequency & Percentage \\
\hline Yes & 28 & 19.44 \\
\hline No & 116 & 80.56 \\
\hline Total & $\mathbf{1 4 4}$ & $\mathbf{1 0 0}$ \\
\hline \multicolumn{2}{|c|}{ Table 7. Stage appropriate Pharmacotherapy } \\
\hline
\end{tabular}

\begin{tabular}{|c|c|c|}
\hline & Frequency & Percentage \\
\hline Indicated and given & 0 & 0 \\
\hline Indicated and not given & 140 & 97.22 \\
\hline Not indicated & 4 & 2.78 \\
\hline Total & 144 & 100 \\
\hline
\end{tabular}

\begin{tabular}{|c|c|c|}
\hline & Frequency & Percentage \\
\hline Indicated and given & 0 & 0 \\
\hline Indicated and not given & 4 & 2.78 \\
\hline Not indicted & 140 & 97.22 \\
\hline Total & 144 & 100 \\
\hline \multicolumn{3}{|c|}{ Table 9. Status of Home Oxygen Therapy } \\
\hline
\end{tabular}

\begin{tabular}{|c|c|c|}
\hline & Frequency & Percentage \\
\hline Yes & 0 & 0 \\
\hline No & 144 & 100 \\
\hline Total & $\mathbf{1 4 4}$ & $\mathbf{1 0 0}$ \\
\hline \multicolumn{2}{|c|}{ Table 10. Stage appropriate Treatment } \\
according to Gold Guidelines \\
\hline
\end{tabular}

\section{DISCUSSION}

The goals of the Global Initiative for Chronic Obstructive Lung Disease (GOLD) are to increase awareness of COPD and decrease morbidity and mortality from the disease. GOLD aims to improve prevention and management of COPD through a concerted worldwide effort of people involved in all facets of health care and health care policy, and to encourage an expanded level of research interest in this highly prevalent disease. A nihilistic attitude toward COPD continues among some health care providers due to the relatively limited success of primary and secondary prevention. Although a serious burden, COPD is under and misdiagnosed in primary care, which likely contributes to the increase in prevalence, morbidity and mortality associated with this disease.

The mean age of subjects in our study was 56.88 with a male predominance of $92.36 \%$ when compared to females (7.64\%). Since tobacco smoking is the most known and established risk factor for COPD, the male predominance is partly explained based on the male: female differences in smoking habits, particularly in India. ${ }^{12}$ Out of the 144 subjects studied $95.83 \%$ were from rural area, whereas $4.17 \%$ from urban area. Jindal reported that the prevalence of COPD was $6.2 \%$ in men and $3.9 \%$ in women in rural area and $4.2 \%$ and $1.6 \%$ respectively in urban area. But there is no such published studies depicting the prevalence of COPD in rural and urban areas of Kerala. Recent Indian Study on Epidemiology of Asthma, Respiratory Symptoms and Chronic Bronchitis in Adults (INSEARECH) reported the overall prevalence of chronic bronchitis in adults > 35 years was $3.49 \%$ and $10 \%$ in Thiruvananthapuram.

Manual labourers account for $96.53 \%$ of the study subjects and 5 subjects were housewives. Relation between COPD and occupation has been described in literature. Evidence from the various well-designed population-based studies has found associations with various workplace exposures and occupations. Exposures include biological and mineral dusts, 13 organic solvents and fumes, silica, coal dust, agricultural dusts, coke oven emissions and tunnelling dusts and fumes. ${ }^{14}$ Implicated occupations included freight, stock and material handlers; transportation related occupations, machine operators and the construction trades. 15

Tobacco smoking is the main cause of chronic obstructive pulmonary disease. Smokers usually belong to three main categories: i.e. current smokers, ex-smokers and never smokers. Current smokers in our study were $54.86 \%$, exsmokers of $41.67 \%$ and only $3.47 \%$ were never smokers. All the subjects were exposed to passive smoking either at home or at workplace. Passive exposure to cigarette smoke is accepted as an independent risk factor for heart disease and lung cancer and has also been implicated in the aetiology of COPD. 16 There is increasing evidence that passive smoking is an important risk factor in chronic respiratory diseases. Evidence is now emerging that COPD may be independently associated with passive smoking exposure. ${ }^{17}$

Majority of the subjects were getting treatment from Government Sector i.e. 85.42\%, whereas those getting treatment from private hospitals are $14.58 \%$. Among the Government Sector, $73.98 \%$ subjects were getting treatment from primary level and those from secondary and tertiary levels are $19.51 \%$ and $6.50 \%$ respectively. Among the private Sector, $80.95 \%$ of the subjects were getting treatment from 
primary level and 19\% from secondary level. None of the study subjects were referred from tertiary level of private Sector. All together 108 subjects i.e. 75\% were on treatment from primary level care, either Government or Private Sector. As per available literature, majority of the COPD patients all over the world is seeking medical care from the primary level care. Primary health care is the first level of contact of the individuals, the family and the community with the National Health System bringing health care as close as possible to where the people live and work. It constitutes the first element of the process of continuing health care and this should get full support from the rest of the health system.

This support would be required in the following areas: (a) Consultation on health problems; (b) Referral of patients to local or other specialised Institutions; (c) Supportive supervision and guidance; and (d) Logistic support and supplies. This shows the importance of strengthening primary level care in case of COPD.

When we assess the pharmacotherapy of the study subjects, it is evident that inhalers are prescribed only for $29.17 \%$. Rest of the patients are getting either short acting or long acting bronchodilators on regular or SOS basis. In the reference study conducted in US hospitals, ${ }^{18}$ the proportion of patients received any type of bronchodilator therapy was $96.7 \%$. But in the Swiss study, less than half the patients in all groups used short-acting bronchodilators. ${ }^{19}$ Antibiotics are indicated only in selected cases of COPD exacerbation. And the proportion of patients getting rationale antibiotic therapy from peripheral health care centres in our study was $2.78 \%$. This shows how antibiotics are misused in peripheral health care levels. But in the reference study, $84.6 \%$ of the patients had received antibiotics, which are guideline recommended. After detailed assessment of the treatment records, the proportion of COPD patients getting stage appropriate pharmacotherapy as per GOLD guidelines (2010) was 19.4\% and $80.5 \%$ had received at least one of the non-recommended medications.

Current treatment guidelines for COPD contain statements about the benefits of pulmonary rehabilitation and recommendations for including such programs in the management of patients with moderate-to-severe disease. Considering the fragmented nature of the healthcare delivery industry in India, there are no big centres of excellence in India providing protocolised rehabilitation services as in the Western world. In the present study, none of the COPD patients have received pulmonary rehabilitation from peripheral health care centres. Several National and International studies have proved that the prescription of pulmonary rehabilitation for COPD patients is very low. In the Swiss study, only $5 \%$ of the COPD patients had received this treatment modality, which has evidence $\mathrm{A}$ in the management protocol. 19

In our study, we have only four COPD patients with definite indication of long-term oxygen therapy. Out of the four, none of them had received home oxygen therapy from peripheral health care centres. And only $2.78 \%$ of the patients are going for review consultation as directed by the treating doctor.

Even though smoking cessation is the most cost effective intervention in the management of COPD, it seems that smoking cessation is not effectively implemented at all levels of health care system. In our study, we assessed the smoking cessation efforts of the medical officers working at the peripheral health care centres. The National Clinical Guideline recommends an intervention for tobacco use known as the 5-As (Ask, Advise, Assess, Assist and Arrange) and this is recommended by GOLD guideline also. The proportion of medical officers utilising each step of this smoking cessation program in our study was: Ask 70.44\%, Advise 47.92\%, Assess 4.17\%, Assist 4.17\% and Arrange 0\%.

And finally, from our study, it was observed that none of the COPD patients are getting ideal stage appropriate management as per GOLD guidelines. However, in the study conducted in US hospitals by Deborah Gesensway and Peter $\mathrm{K}$. Lindenauer, the proportion of COPD patients getting ideal care as per GOLD guidelines is only $33 \%$.

\section{Limitations of the Study}

1. Reference population constitutes COPD patients from Trivandrum and neighbouring two districts.

2. Female COPD patients recruited are low in number, most probably due to misdiagnosis of COPD as asthma in the peripheral health care centres.

3. Even though some of the COPD patients are getting treatment from peripheral health centres, they are excluded from the study due to lack of treatment details.

4. We could not assess the awareness of the medical officers working in peripheral health care centres regarding GOLD guidelines and its importance.

5. The study population is unlikely to reflect the general population of Kerala.

6. As the study population was derived from Government Medical College, Trivandrum, they are likely to represent the lower socio-economic strata.

7. Addition of data on high and middle income group may improve the results on awareness of COPD.

\section{CONCLUSION}

The present study assesses the proportion of COPD patients getting stage appropriate management as per GOLD guidelines from the peripheral health care systems. The study demonstrates that most of the patients lack awareness about COPD. Our study shows that none of the COPD patients are getting ideal treatment as per guidelines from the peripheral health care centres. Even though GOLD guidelines of COPD have been accepted worldwide, the dissemination and application of these guidelines at peripheral level in India is not happening.

\section{REFERENCES}

[1] World Health Report. Geneva: World Health Organization. Available from URL: http://www.who.int/whr/2000/en/ statistics.htm; 2000.

[2] Lopez AD, Shibuya K, Rao C, et al. Chronic obstructive pulmonary disease: current burden and future projections. Eur Respir J 2006;27(2):397- 412.

[3] World health statistics 2008. http://www.who.int.

[4] Global initiative for chronic obstructive lung disease, version, page no: 2, 2010.

[5] Wig KL, Guleria JS, Bhasin RC, et al. Certain clinical and epidemiological patterns of chronic obstructive lung disease as seen in Northern India. Indian J Chest Dis 1964;6:183-94. 
[6] Viswanathan R. Epidemiology of chronic bronchitis: morbidity survey in Patna urban area. Indian J Med Res 1966;54:105-11.

[7] Radha TG, Gupta CK, Singh A, et al. Chronic bronchitis in an urban locality of New Delhi-an epidemiological survey. Indian J Med Res 1977;66(2):273-85.

[8] Jindal SK. A field study on follow up at 10 years of prevalence of chronic obstructive pulmonary disease \& peak expiratory flow rate. Indian J Med Res 1993;98:20-6.

[9] Thiruvengadam KV, Raghava TP, Bhardwaj KV. Survey of prevalence of chronic bronchitis in Madras city. In: Viswanathan R, Jaggi OP, (eds). Advances in chronic obstructive lung disease. Delhi: asthma and bronchitis foundation of India 1977:59-6.

[10] Ray D, Abel R, Selvaraj KG. A 5-yr prospective epidemiological study of chronic obstructive pulmonary disease in rural south India. Indian J Med Res 1995;101:238-44.

[11] Jindal SK, Aggarwal AN, Gupta D, et al. Indian study on epidemiology of asthma, respiratory symptoms and chronic bronchitis in adults (INSEARCH). Int J Tuberc Lung Dis 2012;16(9):1270-7.

[12] Jindal SK, Aggarwal AN, Chaudhry $\mathrm{K}$, et al. A multicentric study on epidemiology of chronic obstructive pulmonary disease and its relationship with tobacco smoking and environmental tobacco smoke exposure. Indian J Chest Dis Allied Sci 2006;48(1):23-9.
[13] Eduard W, Pearce N, Douwes J. Chronic bronchitis, COPD, and lung function in farmers: the role of biological agents. Chest 2009;136(3):716-25.

[14] Blanc PD, Toren K. Occupation in chronic obstructive pulmonary disease and chronic bronchitis: an update. Int J Tuberc Lung Dis 2007;11(3):251-7.

[15] Hnizdo E, Sullivan PA, Bang KM, et al. Association between chronic obstructive pulmonary disease and employment by industry and occupation in the US population: a study of data from the third national health and nutrition examination survey. Am J Epidemiol 2002;156(8):738-46.

[16] Hackshaw AK, Law MR, Wald NJ. The accumulated evidence on lung cancer and environmental tobacco smoke. BMJ 1997;315:980.

[17] Larsson ML, Loit LH, Meren M, et al. Passive smoking and respiratory symptoms in the FinEsS study. Eur Respir J 2003;21(4):672-6.

[18] Gesensway D, Peter K, Lindenauer. In the world of quality improvement, is COPD being left behind. Today's Hospitalist 2006.

[19] Jochmann A, Neubauer F, Miedinger D, et al. General practitioners' adherence to the COPD GOLD guidelines: baseline data from the swiss COPD cohort study. Swiss Medical Weekly 2010. 